\title{
Clinical outcomes and changes in lung function after segmentectomy versus lobectomy for lung cancer cases
}

\author{
Bo Deng, MD, PhD, ${ }^{\mathrm{a}, \mathrm{b}}$ Stephen D. Cassivi, MD, ${ }^{\mathrm{c}}$ Mariza de Andrade, PhD, ${ }^{\mathrm{d}}$ Francis C. Nichols, MD, ${ }^{\mathrm{c}}$ \\ Victor F. Trastek, MD, ${ }^{\mathrm{c}}$ Yi Wang, MD, MS, ${ }^{\mathrm{a}, \mathrm{e}}$ Jason A. Wampfler, BS, ${ }^{\mathrm{d}}$ Shawn M. Stoddard, RN, ${ }^{\mathrm{a}}$ \\ Dennis A. Wigle, MD, PhD, ${ }^{\mathrm{c}}$ Robert K. Shen, $\mathrm{MD},{ }^{\mathrm{c}}$ Mark S. Allen, $\mathrm{MD},{ }^{\mathrm{c}}$ Claude Deschamps, $\mathrm{MD},{ }^{\mathrm{c}}$ and \\ Ping Yang, $\mathrm{MD}, \mathrm{PhD}^{\mathrm{a}}$
}

Objective: We compared the clinical outcomes and changes in pulmonary function test (PFT) results after segmentectomy or lobectomy for non-small cell lung cancer.

Methods: The retrospective study included 212 patients who had undergone segmentectomy (group S) and
2336 patients who had undergone lobectomy (group L) from 1997 to 2012 . The follow-up and medical record
data were collected. We used all the longitudinal PFT data within 24 months postoperatively and performed
linear mixed modeling. We analyzed the 5-year overall and disease-free survival in stage IA patients.
We used propensity score case matching to minimize the bias due to imbalanced group comparisons.

Results: During the perioperative period, 1 death $(0.4 \%)$ in group S and $7(0.3 \%)$ in group L occurred. The hospital stay for the 2 groups was similar (median, 5.0 vs 5.0 days; range, 2-99 vs 2-58). The mean overall and disease-free survival period of those with T1a after segmentectomy or lobectomy seemed to be similar (4.2 vs 4.5 years, $P=.06$; and 4.1 vs 4.4 years, $P=.07$, respectively). Compared with segmentectomy, lobectomy yielded marginally significantly better overall (4.4 vs 3.9 years, $P=.05)$ and disease-free (4.1 vs 3.6 years; $P=.05$ ) survival in those with T1b. We did not find a significantly different effect on the PFTs after segmentectomy or lobectomy.

Conclusions: Both surgical types were safe. We would advocate lobectomy for patients with stage IA disease, especially those with $\mathrm{T} 1 \mathrm{~b}$. A retrospective study with a large sample size and more detailed information should be conducted for PFT evaluation, with additional stratification by lobe and laterality. (J Thorac Cardiovasc Surg 2014;148:1186-92)

Supplemental material is available online.

Lobectomy was traditionally considered the standard surgical procedure for primary non-small cell lung cancer (NSCLC), ${ }^{1}$ until segmental resection was reported. ${ }^{2}$ Since

\footnotetext{
From the Division of Epidemiology, ${ }^{a}$ Department of Health Sciences Research, Mayo Clinic College of Medicine, Rochester, Minn; Department of Thoracic Surgery, ${ }^{b}$ Institute of Surgery Research, Daping Hospital, Third Military Medical University, Chongqing, People's Republic of China; Division of General Thoracic Surgery, ${ }^{\text {c }}$ Department of Surgery, Mayo Clinic College of Medicine, Rochester, Minn; Division of Biomedical Statistics and Informatics, ${ }^{\mathrm{d}}$ Department of Health Sciences Research, Mayo Clinic College of Medicine, Rochester, Minn; and Division of Preventive Medicine, ${ }^{\text {e }}$ School of Environmental Science and Public Health, Wenzhou Medical University, Wenzhou, Zhejiang, People's Republic of China.

The present study was supported by the US National Institutes of Health (grants R03 CA77118, R01 CA80127, and R01 CA84354), Mayo Clinic Foundation, and Third Military Medical University (MiaoPu project).

Disclosures: Authors have nothing to disclose with regard to commercial support.

Received for publication Oct 11, 2013; revisions received March 6, 2014; accepted for publication March 12, 2014; available ahead of print April 18, 2014.

Address for reprints: Ping Yang, MD, PhD, Division of Epidemiology, Department of Health Sciences Research, Mayo Clinic College of Medicine, 200 First St SW, Rochester, MN 55905 (E-mail: yang.ping@mayo.edu).

$0022-5223 / \$ 36.00$

Copyright (c) 2014 by The American Association for Thoracic Surgery

http://dx.doi.org/10.1016/j.jtcvs.2014.03.019
}

the introduction of segmentectomy, controversy has remained regarding the optimal surgical approach for early-stage NSCLC. ${ }^{3}$ Advocates for lobectomy have demonstrated the reduced risk of local recurrence and better prognosis compared with segmentectomy. ${ }^{1,4}$ For instance, the recurrence rates were appreciably greater in those who had undergone sublobar resection compared with lobectomy $(17.2 \%$ vs $6.4 \%) .{ }^{4}$ The supporters for segmentectomy believe the 2 operations have similar curative effects ${ }^{3,5-7}$ but that segmentectomy offers better pulmonary functional preservation. 8,9

Our recent retrospective study of a cohort of 113 patients with NSCLC (stage IA-IIIB), who had undergone segmentectomy for primary lung cancer from 1999 to 2004, reported no perioperative mortality, significant comorbidities in 62 patients $(55 \%)$, and tumor recurrence in 39 patients $(35 \%) .{ }^{10}$ In the present study, we sequentially compared the clinical outcomes and evaluated the changes in the pulmonary function tests (PFTs) after segmentectomy or lobectomy for the cohort of 2548 patients who were enrolled from 1997 to 2012.

Because surgical approaches (ie, thoracotomy or videoassisted thoracic surgery [VATS]) can also potentially lead to a significant discrepancy in complications or 


\section{Abbreviations and Acronyms \\ BMI = body mass index \\ DFS $=$ disease-free survival \\ FEV1 = forced expiratory volume in 1 second \\ NSCLC $=$ non-small cell lung cancer \\ OS $=$ overall survival \\ PFT = pulmonary function test \\ PS = propensity scores \\ VATS $=$ video-assisted thoracic surgery}

PFTs, ${ }^{11,12}$ in the present study, we stratified the patients into thoracotomy and VATS groups for the analysis.

\section{METHODS}

\section{Patient and Data Collection}

The Mayo Clinic institutional review board reviewed and approved the study protocol. A detailed study protocol has been previously reported. ${ }^{13}$ In brief, from 1997 to 2012 at Mayo Clinic (Rochester, Minn), all patients underwent computed tomography before surgery. Most patients underwent PFTs and standard investigations for preoperative lung cancer staging, such as positron emission tomography-computed tomography fusion scans. ${ }^{14}$ The medical record data included age, gender, smoking status, operative procedure, mortality, complications, length of hospital stay, histopathologic features, and preoperative and postoperative PFT results. The patients underwent disease staging postoperatively according to the seventh edition of the TNM staging system of the American Joint Committee on Cancer.

We stratified the patients into open thoracotomy (eg, muscle-sparing thoracotomy [posterolateral or serratus anterior incision]) or VATS groups for analysis, according to our previously published protocols. ${ }^{10,15}$ All the operations were performed at Mayo Clinic. Simple wedge resection without anatomic dissection of the bronchovascular structures was not incorporated as segmentectomy. Mediastinal lymphadenectomy was a standard procedure after lobectomy or segmentectomy. Perioperative mortality included all deaths occurring within 30 days of the operative procedure and deaths that occurred later during the initial perioperative hospitalization.

The PFTs included the percentage of predicted forced expiratory volume in 1 second (FEV1), percentage of predicted forced vital capacity, and percentage of predicted diffusion capacity of the lung for carbon monoxide. Specifically, we focused on the PFTs performed at 2 points: within 1 month before surgery and within 24 months postoperatively. Thereafter, we used all the longitudinal data (repeated measures) we had and performed linear mixed modeling, including the variables (ie, surgery type and interval from treatment to the PFT).

The follow-up and recurrence data were collected through detailed medical record data abstraction and self-administered questionnaires, including present health and treatment update starting within 6 months after diagnosis and annually thereafter. For deceased patients, follow-up questionnaires were sent to the next-of-kin to collect the information regarding the patient's death. When conducting the survival analysis, we included the patients with stage IA and used the 5-year overall survival (OS) and 5-year disease-free survival (DFS) data (ie, survival with freedom from recurrence or progression). The patients whose follow-up time was $<30$ days or who had died within 30 days after surgery were excluded from the OS and DFS analyses.

\section{Statistical Analysis}

The descriptive statistics for categorical variables are reported as frequencies and percentages and continuous variables as mean \pm standard deviation. Positive rates were compared using the chi-square test or Fisher's exact test. Between groups, analyses of variance were performed using the Student $t$ test according to a normal distribution or Wilcoxon's signed rank test. OS and DFS were estimated using the Kaplan-Meier survival method. We matched the cases between the imbalanced groups by propensity scores (PSs) using the greedy algorithm. ${ }^{16}$ Before matching, we calculated the PSs, incorporating the variables that could potentially affect the clinical outcomes or PFT results, including age, gender, smoking status, body mass index (BMI), lung side and lobe, cell type, tumor grade, and surgical approach. Thereafter, we used 3:1 matching between the 2 groups. All data entry and analyses were performed using Statistical Analysis Systems, version 9.3, software (SAS Institute, Inc, Cary, NC).

\section{RESULTS}

\section{Demographic, Pathologic, and Clinical Characteristics}

The present study included 212 patients who had undergone segmentectomy (group S) and 2336 patients who had undergone lobectomy (group L). The demographic and pathologic characteristics of the patients are listed in Table E1. Figure 1 indicates the year-proportion of each approach and surgery type, showing that the use of VATS had increased remarkably since 2005 .

In the perioperative period, 1 death $(0.4 \%)$ in group $\mathrm{S}$ and $7(0.3 \%)$ in group L occurred. In addition, the hospital stay for the 2 was similar (median, 5.0 vs 5.0; range, 2-99 vs $2-58 ; P=.31)$.

\section{Perioperative Complications}

The complications after VATS $(\mathrm{n}=301)$ and thoracotomy $(\mathrm{n}=2247)$ are listed in Table 1 . The clinical features

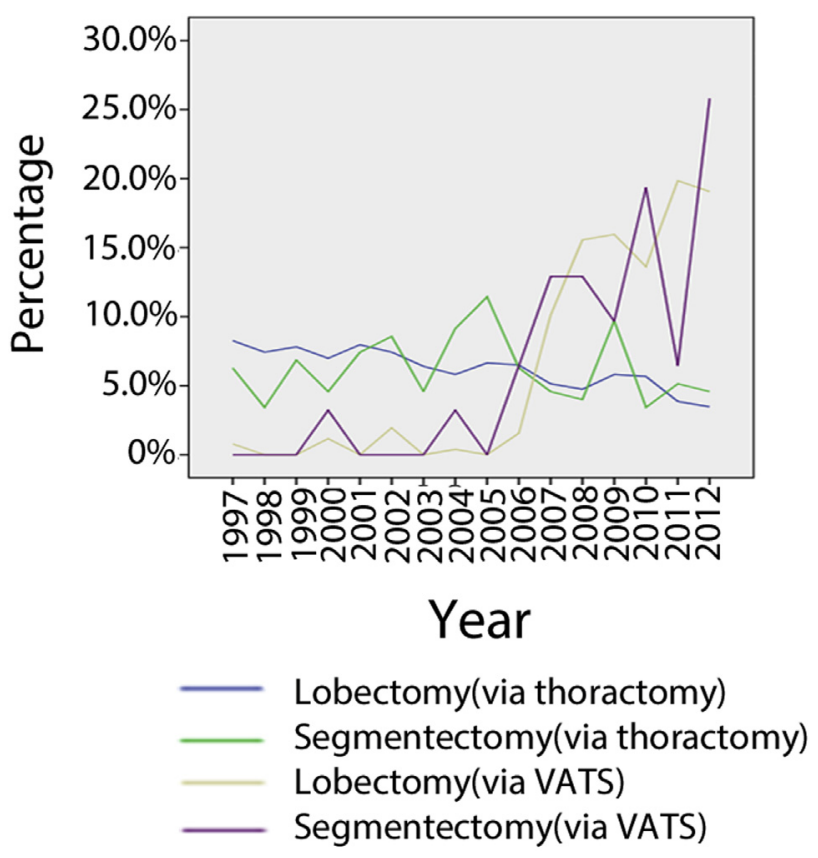

FIGURE 1. Proportion of surgery types of 2509 cases, 1997 to 2012, Mayo Clinic (Minnesota). VATS, Video-assisted thoracic surgery. 
TABLE 1. Perioperative complications of VATS versus thoracotomy

\begin{tabular}{|c|c|c|c|c|c|c|}
\hline \multirow[b]{2}{*}{ Variable } & \multicolumn{3}{|c|}{ Total } & \multicolumn{3}{|c|}{ Matched cases by PS } \\
\hline & $\operatorname{VATS}(\mathbf{n}=301)$ & Thoracotomy $(n=2247)$ & $P$ value & $\operatorname{VATS}(n=301)$ & Thoracotomy $(n=903)$ & $P$ value \\
\hline No complications & $222(73.8)$ & $1439(64.0)$ & $<.01 *$ & $222(73.8)$ & $562(62.2)$ & $<.01^{*}$ \\
\hline Atrial fibrillation $\dagger$ & $28(9.3)$ & $325(14.5)$ & $.01 *$ & $28(9.3)$ & $142(15.7)$ & $<.01 *$ \\
\hline Air leak $>7 \mathrm{~d} \ddagger$ & $33(11.0)$ & $218(9.7)$ & .49 & $33(11.0)$ & $96(10.6)$ & .87 \\
\hline Pulmonary complications $\S$ & $8(2.7)$ & $165(7.3)$ & $<.01 *$ & $8(2.7)$ & $64(7.1)$ & $<.01 *$ \\
\hline Anesthetic complications $\|$ & $13(4.3)$ & $64(2.8)$ & .16 & $13(4.3)$ & $25(2.8)$ & .18 \\
\hline Chylothorax or hemothorax & $5(1.7)$ & $35(1.6)$ & .89 & $5(1.7)$ & $8(0.9)$ & .26 \\
\hline Acute renal failure & $2(0.7)$ & $18(0.9)$ & .80 & $2(0.7)$ & $6(0.7)$ & 1.00 \\
\hline Gastrointestinal system $\llbracket$ & $2(0.7)$ & $22(1.0)$ & .59 & $2(0.7)$ & $11(1.2)$ & .42 \\
\hline Urinary retention & $3(1.0)$ & $16(0.7)$ & .59 & $3(1.0)$ & $6(0.7)$ & .56 \\
\hline Acute myocardial infarction & $0(0.0)$ & $12(0.5)$ & .20 & $0(0.0)$ & $5(0.6)$ & .19 \\
\hline Wound\# & $0(0.0)$ & $10(0.4)$ & .25 & $0(0.0)$ & $6(0.7)$ & .16 \\
\hline Embolism** & $2(0.7)$ & $9(0.4)$ & .51 & $2(0.7)$ & $3(0.3)$ & .43 \\
\hline Empyema & $0(0.0)$ & $5(0.2)$ & .41 & $0(0.0)$ & $0(0.0)$ & - \\
\hline
\end{tabular}

Data presented as $\mathrm{n}(\%)$. VATS, Video-assisted thoracic surgery; $P S$, propensity score. *Statistically significant. $\dagger$ Development of postoperative atrial fibrillation. $\ddagger$ Prolonged air leak lasting $>7$ days. $§$ Pneumonia and its consequences (ie, adult respiratory distress syndrome or respiratory failure). ||Postoperative confusion, vocal cord paralysis, or alcohol withdrawal symptoms. GGastroparesis or ileus. \#Wound dehiscence or infection. **Deep venous thrombosis or pulmonary embolism.

of these patients are presented in Table E2. We matched 2 groups who had undergone the 2 approaches using PS matching and incorporating the variables of age, gender, smoking status, BMI, tumor stage, and other comorbidities that could potentially affect the incidence of perioperative complications. ${ }^{17,18}$ After PS matching, no significant difference was found in these variables between the VATS and thoracotomy groups. Before matching, $73.8 \%$ of the patients in the VATS group had had no complications compared with $64.0 \%$ of those in the thoracotomy group $(P<.01)$. The trend was similar after matching $(73.8 \%$ vs $62.2 \%, P<.01)$. In addition, the incidence of atrial fibrillation and pulmonary complications in the thoracotomy group was remarkably greater than in the VATS group, before or after matching (Table 1).
Similarly, we evaluated the complications of groups $\mathrm{S}$ and L stratified by the thoracotomy and VATS approach. We matched the patients in groups $\mathrm{S}$ and L using PS matching and incorporating age, gender, smoking status, BMI, tumor stage, and other comorbidities (data for the thoracotomy approach are listed in Table E3 and those for the VATS approach in Table E4). After PS matching, no significant difference was found in the clinical variables between groups $\mathrm{S}$ and $\mathrm{L}$. Regarding the thoracotomy approach, no significant difference was found in the incidence of complications between groups $\mathrm{S}$ and $\mathrm{L}$ before matching (Table 2). However, segmentectomy seemed to result in fewer complications than lobectomy after matching $(P=.02$; Table 2). Regarding the VATS approach, the incidence of air leaks and pulmonary

TABLE 2. Postoperative complications of segmentectomy versus lobectomy (thoracotomy approach)

\begin{tabular}{|c|c|c|c|c|c|c|}
\hline \multirow[b]{2}{*}{ Variable } & \multicolumn{3}{|c|}{ Total } & \multicolumn{3}{|c|}{ Matched cases by PS } \\
\hline & Group L $(\mathbf{n}=\mathbf{2 0 7 0})$ & Group S $(n=177)$ & $P$ value & Group L $(\mathbf{n}=\mathbf{5 3 1})$ & Group S $(n=177)$ & $P$ value \\
\hline No complications & 1318 (63.7) & $120(67.8)$ & .27 & $310(58.4)$ & $120(67.8)$ & $.02 *$ \\
\hline Atrial fibrillation $\dagger$ & $301(14.5)$ & $24(13.6)$ & .72 & $98(18.5)$ & $24(13.6)$ & .14 \\
\hline Air leak $>7 \mathrm{~d} \ddagger$ & $204(9.9)$ & $13(7.3)$ & .28 & $56(10.5)$ & $13(7.3)$ & .21 \\
\hline Pulmonary complications $\S$ & $149(7.2)$ & $16(9.0)$ & .37 & $52(9.8)$ & $16(9.0)$ & .77 \\
\hline Anesthetic complications $\|$ & $59(2.9)$ & $5(2.8)$ & .98 & $19(3.6)$ & $5(2.8)$ & .63 \\
\hline Chylothorax or hemothorax & 34 (1.6) & $1(0.6)$ & .27 & $4(0.8)$ & $1(0.6)$ & .79 \\
\hline Acute renal failure & $18(0.9)$ & $0(0.0)$ & .21 & $3(0.6)$ & $0(0.0)$ & .31 \\
\hline Gastrointestinal system $\llbracket$ & $20(1.0)$ & $2(1.1)$ & .83 & $6(1.1)$ & $2(1.1)$ & 1.00 \\
\hline Urinary retention & $15(0.7)$ & $1(0.6)$ & .81 & $5(0.9)$ & $1(0.6)$ & .64 \\
\hline Acute myocardial infarction & $12(0.6)$ & $0(0.0)$ & .31 & $2(0.4)$ & $0(0.0)$ & .41 \\
\hline Wound\# & $8(0.4)$ & $2(1.1)$ & .15 & $1(0.2)$ & $2(1.1)$ & .10 \\
\hline Embolism** & $7(0.3)$ & $2(1.1)$ & .11 & $1(0.2)$ & $2(1.1)$ & .10 \\
\hline Empyema & $5(0.2)$ & $0(0.0)$ & .51 & $1(0.2)$ & $0(0.0)$ & .56 \\
\hline
\end{tabular}

Data presented as n (\%). PS, Propensity score; $L$, lobectomy; $S$, segmentectomy. *Statistically significant. $\dagger$ Development of postoperative atrial fibrillation. $\Varangle$ Prolonged air leak lasting $>7$ days. $§$ Pneumonia and its consequences (ie, adult respiratory distress syndrome or respiratory failure). \|Postoperative confusion, vocal cord paralysis, or alcohol withdrawal symptoms. $\lceil$ Gastroparesis or ileus. \#Wound dehiscence or infection. **Deep venous thrombosis or pulmonary embolism. 
TABLE 3. Postoperative complications of segmentectomy versus lobectomy (VATS approach)

\begin{tabular}{|c|c|c|c|c|c|c|}
\hline \multirow[b]{2}{*}{ Variable } & \multicolumn{3}{|c|}{ Total } & \multicolumn{3}{|c|}{ Matched cases by PS } \\
\hline & Group L $(n=266)$ & Group S $(\mathbf{n}=\mathbf{3 5})$ & $P$ value & Group L $(n=105)$ & Group $S(n=35)$ & $P$ value \\
\hline No complications & $197(74.1)$ & $24(68.6)$ & .49 & $76(72.4)$ & $24(68.6)$ & .67 \\
\hline Atrial fibrillation* & $26(9.8)$ & $2(5.7)$ & .44 & $11(10.5)$ & $2(5.7)$ & .40 \\
\hline Air leak $>7 \mathrm{~d} \dagger$ & $25(9.4)$ & $8(22.9)$ & $.02 \ddagger$ & $8(7.6)$ & $8(22.9)$ & $.01 \ddagger$ \\
\hline Pulmonary complications $\S$ & $5(1.9)$ & $3(8.6)$ & $.02 \ddagger$ & $0(0.0)$ & $3(8.6)$ & $<.01 \ddagger$ \\
\hline Anesthetic complications $\|$ & $11(4.1)$ & $2(5.7)$ & .66 & $7(6.7)$ & $2(5.7)$ & .84 \\
\hline Chylothorax or hemothorax $\llbracket$ & $4(1.6)$ & $0(0.0)$ & .47 & $0(0.0)$ & $0(0.0)$ & - \\
\hline Acute renal failure & $1(0.4)$ & $1(2.9)$ & .09 & $0(0.0)$ & $1(2.9)$ & .08 \\
\hline Gastrointestinal system\# & $2(0.8)$ & $0(0.0)$ & .61 & $2(1.9)$ & $0(0.0)$ & .41 \\
\hline Urinary retention & $3(1.1)$ & $0(0.0)$ & .53 & $0(0.0)$ & $0(0.0)$ & - \\
\hline Embolism** & $2(0.8)$ & $0(0.0)$ & .61 & $0(0.0)$ & $0(0.0)$ & - \\
\hline
\end{tabular}

Data presented as n (\%). PS, Propensity score; $L$, lobectomy; $S$, segmentectomy. * Development of postoperative atrial fibrillation. $\dagger$ Prolonged air leak lasting $>7$ days. $\ddagger$ Statistically significant. $§$ Pneumonia and its consequences (ie, adult respiratory distress syndrome or respiratory failure). ||Postoperative confusion, vocal cord paralysis, or alcohol withdrawal symptoms. $\uparrow$ Gastroparesis or ileus. \#Wound dehiscence or infection. **Deep venous thrombosis or pulmonary embolism.

complications was significantly greater in group $\mathrm{S}$ than in group L before and after matching (Table 3).

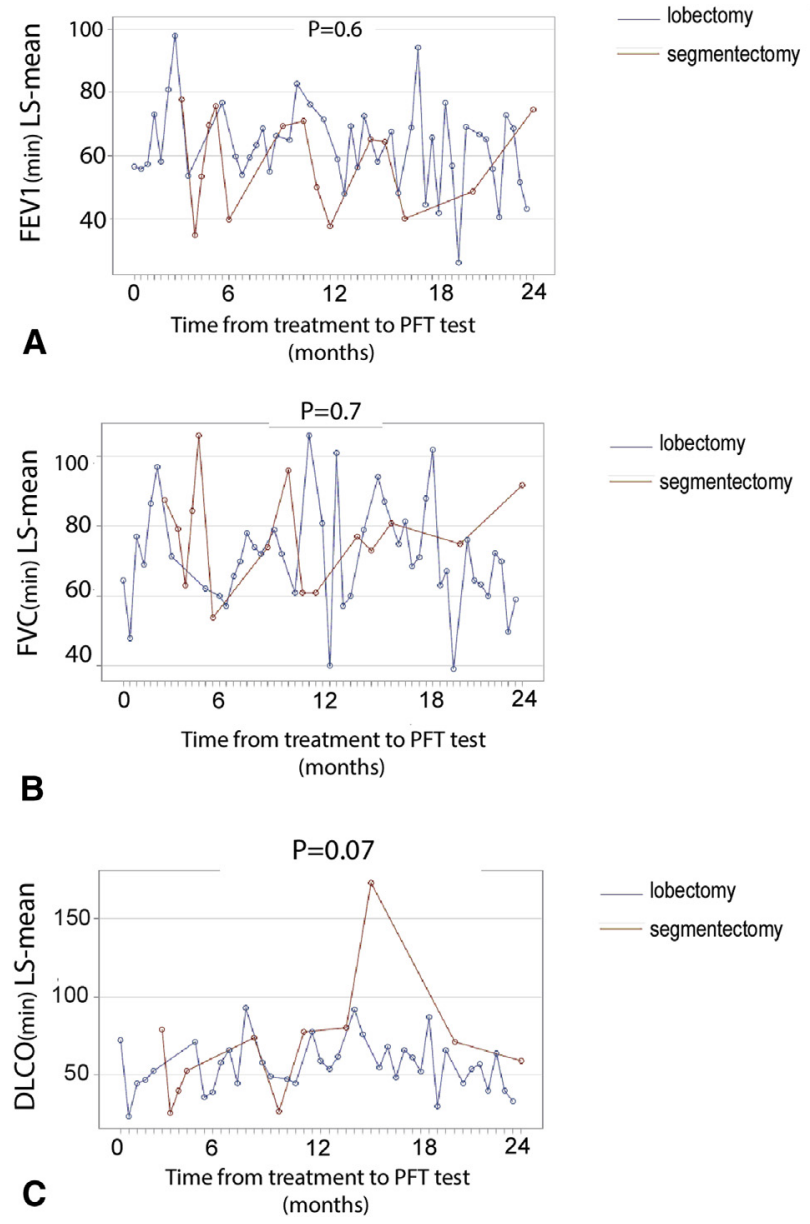

FIGURE 2. No significant difference was found in the trend of postoperative pulmonary function test $(P F T)$ data. A, Forced expiratory volume in 1 second (FEVI), (B) forced vital capacity $(F V C)$, and (C) diffusing capacity of the lung for carbon monoxide $(D L C O)$ after segmentectomy or lobectomy. $L S$, Least squares.

\section{Postoperative Changes in PFT Results}

For the postoperative changes in the PFT results, we only analyzed the thoracotomy group. We did not analyze the data after VATS owing to the small sample size. A total of 264 patients had undergone both preoperative PFTs conducted 1 month before surgery and postoperative PFTs conducted within 24 months after surgery. Of the 264 patients, 17 and 247 were in group S and L, respectively. No significant difference in age, gender, smoking status, BMI, tumor stage, lobe and side, or chronic obstructive pulmonary disease was found between groups $\mathrm{S}$ and $\mathrm{L}$ after we had matched these variables (Table E5). Additionally, no significant difference was found in the preoperative PFT data after PS matching (Table E5).

Linear mixed modeling indicated that no significant trend was present within each group (the trend of blue or red curve) or difference of the trend (difference between blue and red curve) in the postoperative PFT data (ie, FEV1, forced vital capacity, and diffusing capacity of the lung for carbon monoxide after segmentectomy or lobectomy; Figure 2). Thus, we did not found a significantly different effect in the PFT results after segmentectomy and lobectomy.

\section{Survival Analysis}

To evaluate the possible effect of tumor size on local recurrence and survival, ${ }^{19,20}$ we stratified the patients with stage IA NSCLC into 2 subsets, T1a and T1b, according to the tumor size.

We matched the PS of groups $\mathrm{S}$ and $\mathrm{L}$, incorporating the variables age, gender, smoking status, BMI, tumor differentiation, side and lobe, surgical approach, and other comorbidities that could potentially affect survival ${ }^{21-23}$ (Table E1). No significant difference was found regarding these variables between groups $\mathrm{S}$ and $\mathrm{L}$ after PS matching (Table E1). Figure 3, $A$ and $B$, indicate that the mean OS and DFS time for those with stage T1a after segmentectomy 


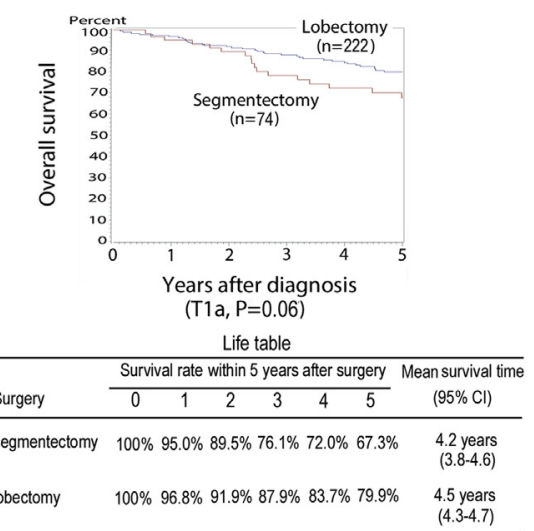

A
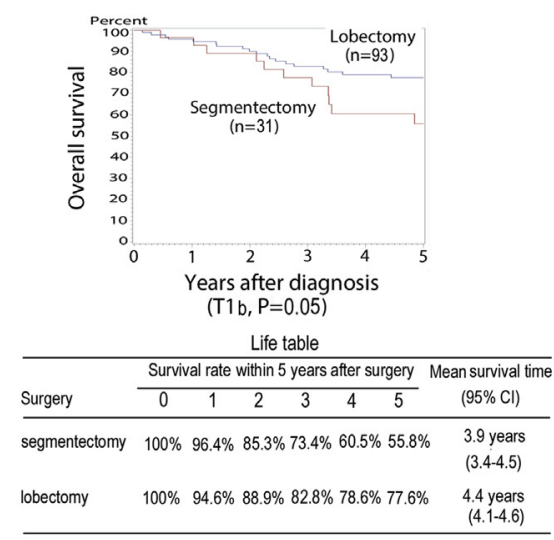

\section{C}

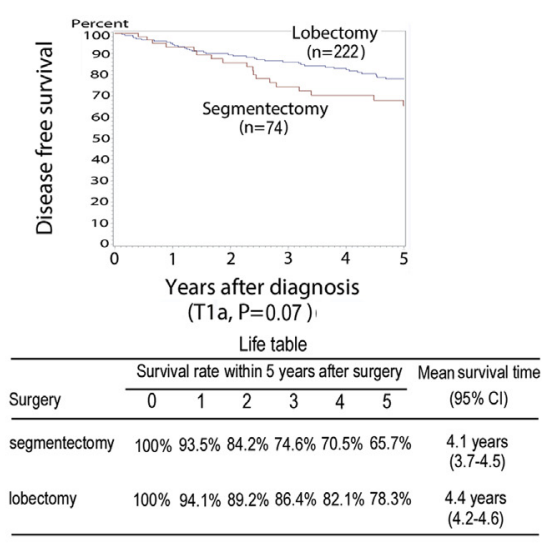

B

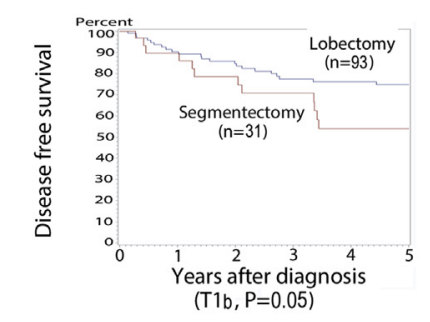

\begin{tabular}{lccccccc}
\hline \multicolumn{7}{c}{ Life table } \\
\hline Surgery & \multicolumn{1}{c}{ Survival rate within 5 years after surgery } & $\begin{array}{c}\text { Mean survival time } \\
(95 \% \mathrm{Cl})\end{array}$ \\
\cline { 2 - 5 } segmentectomy & $100 \%$ & $86.0 \%$ & $74.6 \%$ & $66.5 \%$ & $54.1 \%$ & $54.1 \%$ & $\begin{array}{c}3.6 \text { years } \\
(3.0-4.3)\end{array}$ \\
lobectomy & $100 \%$ & $89.2 \%$ & $83.5 \%$ & $77.4 \%$ & $76.1 \%$ & $74.7 \%$ & $\begin{array}{c}4.1 \text { years } \\
(3.8-4.5)\end{array}$ \\
\hline
\end{tabular}

D

FIGURE 3. Overall and disease-free survival of patients with stage T1a and T1b after segmentectomy or lobectomy. No significant difference was found in overall or disease-free survival for those with T1a after (A) segmentectomy or (B) lobectomy. A marginally significant difference was found in overall and disease-free survival for those with stage T1b after (C) segmentectomy or (D) lobectomy. CI, Confidence interval.

or lobectomy seemed to be similar (4.2 vs 4.5 years, $P=.06$; and 4.1 vs 4.4 years, $P=.07$, respectively). However, compared with segmentectomy, lobectomy yielded marginally significantly better OS (4.4 vs 3.9 years, $P=.05)$ and DFS (4.1 vs 3.6 years, $P=.05)$ in those with stage T1b (Figure 3, $C$ and $D$ ).

\section{DISCUSSION}

The surgical strategies of early NSCLC should include 2 contradictory aspects: maximum resection to reduce the risk of recurrence and minimal invasion to preserve pulmonary function. Thus far, segmentectomy and lobectomy have been the 2 major operations for early NSCLC; however, the choice for the optimal surgical approach has remained inconclusive. A controversy began regarding the best surgical treatment option for early NSCLC after the publication of a prospective randomized study that had compared sublobar resection (segmentectomy and wedge resection) with lobectomy for stage IA NSCLC. ${ }^{4}$ The results indicated that the recurrence rates were appreciably greater for the sublobar resection group than for the lobectomy group $(17.2 \%$ vs
$6.4 \%$ ). However, no statistically significant survival difference was found after sublobar resection and lobectomy. A population-based study of those with stage I demonstrated that lobectomy conferred superior unadjusted OS $(P<.0001)$ and cancer-specific 5-year survival compared with segmentectomy $(P=.0053) .{ }^{1}$ Nevertheless, other studies have obtained different results. ${ }^{3,5,6}$ In a Japanese study, Yamashita and colleagues ${ }^{5}$ reported a similar recurrent and metastatic rate for those with stage I between the segmentectomy and lobectomy groups $(7.9 \%$ vs $5.6 \%$, $P>.05$; and $5.3 \%$ vs $5.6 \%, P>.05$ ). Additionally, in an American study, Shapiro and colleagues ${ }^{3}$ demonstrated a similar recurrence rate for those with stage I between the segmentectomy and lobectomy groups $(17.2 \%$ vs $20.4 \%$, $P=.71)$. In a Chinese study, Zhong and colleagues ${ }^{6}$ reported that no significant difference was observed in 5 -year OS or DFS in those with stage I after segmentectomy or lobectomy. Okada and colleagues ${ }^{24}$ and Warren and Faber $^{25}$ reported that segmentectomy could be safe and considered for patients with stage I NSCLC, with tumors $<3 \mathrm{~cm}$ and $<2 \mathrm{~cm}$. 
With regard to the effect of the 2 operations on postoperative function, the results and conclusions are very complicated. Harada and colleages ${ }^{8}$ found that the extent of the removed lung parenchyma directly affected postoperative functional loss and that segmentectomy offered significantly better functional preservation compared with lobectomy. In another study, Yoshimoto and colleagues ${ }^{9}$ demonstrated that postoperative FEV1 had increased after lobectomy or segmentectomy on the left upper lobe but had decreased after right upper lobectomy. However, lobectomy or segmentectomy on the bilateral lower lobe had no effect on postoperative FEV1. ${ }^{9}$ Kashiwabara and colleagues ${ }^{26}$ concluded that segmentectomy should be considered for patients with cT1N0 NSCLC with a normal $(>80 \%)$ predicted postoperative FEV1. In patients with a predicted normal value of FEV1 $<70 \%$, segmentectomy offered no functional advantages compared with lobectomy. Collectively, the effect of the PFT results postoperatively will depend on the emphysema status, operation side and lobe, and surgical type.

We retrospectively studied the clinical outcomes and postoperative changes in the PFT results from a cohort of 2548 patients. We acknowledge the limitations of the present study. It was a retrospective comparative analysis rather than a prospective randomized comparison. To minimize the selection bias, we used a PS case matching procedure and compared the matched groups. The PS case is regarded as the best method to address the selection bias issue in the context of a retrospective nonrandomized comparison. ${ }^{16}$ Generally, many-to-one matching on the PS has ranged from $4: 1$ to $1: 1{ }^{27}$ Increasing the many will tend to increase the bias in the estimated treatment effect. In contrast, increasing the many will decrease the sampling variability ${ }^{27}$ and improve the precision of the hazard ratio. ${ }^{28}$ We have presented the results using 3:1 matching between the groups.

In the present study, we found very few patients experienced perioperative death after segmentectomy $(0.4 \%)$ or lobectomy $(0.3 \%)$, suggesting that either of the procedures is safe. The VATS approach resulted in fewer perioperative complications than did thoracotomy. The incidence of complications after open segmentectomy was less than that after open lobectomy after PS matching. However, the incidence of air leak or pulmonary complications was greater in those who had undergone VATS segmentectomy compared with VATS lobectomy, probably because of the learning curve.

Among those with T1a NSCLC, OS or DFS after segmentectomy or lobectomy seemed similar. However, compared with segmentectomy, lobectomy rendered relatively better OS or DFS in those with stage T1b NSCLC.

We acknowledge the limitations of PFT analysis in the present study, including that the number of patients in group $\mathrm{S}$ was quite low, and we had no information regarding the types of segmentectomy used. Therefore, we could not stratify the cases according to side and lobe. However, at the very least, we did not found a significant difference in the PFT results after segmentectomy or lobectomy. Therefore, a retrospective study with a large sample size and more detailed information (eg, types of segmentectomy) should be conducted for PFT evaluation, with additional stratification by lobe and laterality.

Collectively, we believe both surgical types are safe. Therefore, we would advocate lobectomy for stage IA NSCLC, especially T1b. Given the disparity in the recurrence rate and survival after the 2 surgical procedures, we agree with Nomori and colleagues ${ }^{29}$ that segmentectomy should be performed with extensive hilar and mediastinal lymph node dissection and a sufficient surgical margin.

The authors appreciate Susan Ernst, MA, for her technical assistance with our report.

\section{References}

1. Whitson BA, Groth SS, Andrade RS, Maddaus MA, Habermann EB, D’Cunha J. Survival after lobectomy versus segmentectomy for stage I non-small cell lung cancer: a population-based analysis. Ann Thorac Surg. 2011;92:1943-50.

2. Jensik RJ, Faber LP, Milloy FJ, Monson DO. Segmental resection for lung cancer: a fifteen-year experience. J Thorac Cardiovasc Surg. 1973;66: 563-72.

3. Shapiro M, Weiser TS, Wisnivesky JP, Chin C, Arustamyan M, Swanson SJ Thoracoscopic segmentectomy compares favorably with thoracoscopic lobectomy for patients with small stage I lung cancer. J Thorac Cardiovasc Surg. 2009; 137:1388-93.

4. Ginsberg RJ, Rubinstein LV. Randomized trial of lobectomy versus limited resection for T1 N0 non-small cell lung cancer. Lung Cancer Study Group. Ann Thorac Surg. 1995;60:615-22; discussion 622-3.

5. Yamashita S, Chujo M, Kawano Y, Miyawaki M, Tokuishi K, Anami K, et al. Clinical impact of segmentectomy compared with lobectomy under complete video-assisted thoracic surgery in the treatment of stage I non-small cell lung cancer. J Surg Res. 2011;166:46-51

6. Zhong C, Fang W, Mao T, Yao F, Chen W, Hu D. Comparison of thoracoscopic segmentectomy and thoracoscopic lobectomy for small-sized stage IA lung cancer. Ann Thorac Surg. 2012;94:362-7.

7. Matsumura Y, Hishida T, Yoshida J, Aokage K, Ishii G, Nagai K. Reasonable extent of lymph node dissection in intentional segmentectomy for small-sized peripheral non-small-cell lung cancer: from the clinicopathological findings of patients who underwent lobectomy with systematic lymph node dissection. J Thorac Oncol. 2012;7:1691-7.

8. Harada H, Okada M, Sakamoto T, Matsuoka H, Tsubota N. Functional advantage after radical segmentectomy versus lobectomy for lung cancer. Ann Thorac Surg. 2005;80:2041-5

9. Yoshimoto K, Nomori H, Mori T, Ohba Y, Shiraishi K, Tashiro K, et al. Postoperative change in pulmonary function of the ipsilateral preserved lung after segmentectomy versus lobectomy. Eur J Cardiothorac Surg. 2010;37: 36-9.

10. Donahue JM, Morse CR, Wigle DA, Allen MS, Nichols FC, Shen KR, et al Oncologic efficacy of anatomic segmentectomy in stage IA lung cancer patient with T1a tumors. Ann Thorac Surg. 2012;93:381-7; discussion 387-8.

11. Ceppa DP, Kosinski AS, Berry MF, Tong BC, Harpole DH, Mitchell JD, et al. Thoracoscopic lobectomy has increasing benefit in patients with poor pulmonary function: a Society of Thoracic Surgeons Database analysis. Ann Surg. 2012;256: 487-93.

12. Handy JR Jr, Asaph JW, Douville EC, Ott GY, Grunkemeier GL, Wu Y Does video-assisted thoracoscopic lobectomy for lung cancer provide improved functional outcomes compared with open lobectomy? Eur J Cardiothorac Surg. 2010;37:451-5. 
13. Yang P, Allen MS, Aubry MC, Wampfler JA, Marks RS, Edell ES, et al. Clinical features of 5,628 primary lung cancer patients: experience at Mayo Clinic from 1997 to 2003. Chest. 2005;128:452-62.

14. Cassivi SD, Allen MS, Vanderwaerdt GD, Ewoldt LL, Cordes ME, Wigle DA, et al. Patient-centered quality indicators for pulmonary resection. Ann Thorac Surg. 2008;86:927-32.

15. Tomaszek SC, Cassivi SD, Shen KR, Allen MS, Nichols FC III, Deschamps C, et al. Clinical outcomes of video-assisted thoracoscopic lobectomy. Mayo Clin Proc. 2009;84:509-13.

16. Austin PC. An introduction to propensity score methods for reducing the effects of confounding in observational studies. Multivariate Behav Res. 2011;46: $399-424$.

17. Okami J, Higashiyama M, Asamura H, Goya T, Koshiishi Y, Sohara Y, et al. Pulmonary resection in patients aged 80 years or over with clinical stage I non-small cell lung cancer: prognostic factors for overall survival and risk factors for postoperative complications. J Thorac Oncol. 2009;4:1247-53.

18. Yano T, Yokoyama H, Fukuyama Y, Takai E, Mizutani K, Ichinose Y. The current status of postoperative complications and risk factors after a pulmonary resection for primary lung cancer: a multivariate analysis. Eur J Cardiothorac Surg. 1997; 11:445-9.

19. Morgensztern D, Waqar S, Subramanian J, Gao F, Trinkaus K, Govindan R. Prognostic significance of tumor size in patients with stage III non-small-cell lung cancer: a Surveillance, Epidemiology, and End Results (SEER) survey from 1998 to 2003. J Thorac Oncol. 2012;7:1479-84.

20. Cuffe S, Bourredjem A, Graziano S, Pignon JP, Domerg C, Ezzalfani M, et al. A pooled exploratory analysis of the effect of tumor size and KRAS mutations on survival benefit from adjuvant platinum-based chemotherapy in node-negative non-small cell lung cancer. J Thorac Oncol. 2012;7:963-72.
21. Radzikowska E, Glaz P, Roszkowski K. Lung cancer in women: age, smoking, histology, performance status, stage, initial treatment and survival: populationbased study of 20,561 cases. Ann Oncol. 2002;13:1087-93.

22. Wang BY, Huang JY, Cheng CY, Lin CH, Ko J, Liaw YP. Lung cancer and prognosis in Taiwan: a population-based cancer registry. J Thorac Oncol. 2013;8:1128-35.

23. Wisnivesky JP, Henschke C, McGinn T, Iannuzzi MC. Prognosis of stage II non-small cell lung cancer according to tumor and nodal status at diagnosis. Lung Cancer. 2005;49:181-6.

24. Okada M, Yoshikawa K, Hatta T, Tsubota N. Is segmentectomy with lymph node assessment an alternative to lobectomy for non-small cell lung cancer of $2 \mathrm{~cm}$ or smaller? Ann Thorac Surg. 2001;71:956-60; discussion 61.

25. Warren WH, Faber LP. Segmentectomy versus lobectomy in patients with stage I pulmonary carcinoma: five-year survival and patterns of intrathoracic recurrence. J Thorac Cardiovasc Surg. 1994;107:1087-93; discussion 93-4.

26. Kashiwabara K, Sasaki J, Mori T, Nomori H, Fujii K, Kohrogi H. Relationship between functional preservation after segmentectomy and volume-reduction effects after lobectomy in stage I non-small cell lung cancer patients with emphysema. J Thorac Oncol. 2009;4:1111-6.

27. Austin PC. Statistical criteria for selecting the optimal number of untreated subjects matched to each treated subject when using many-to-one matching on the propensity score. Am J Epidemiol. 2010;172:1092-7.

28. Suresh K, Suresh G, Thomas SV. Design and data analysis 1 study design. Ann Indian Acad Neurol. 2012;15:76-80.

29. Nomori H, Mori T, Izumi Y, Kohno M, Yoshimoto K, Suzuki M. Is completion lobectomy merited for unanticipated nodal metastases after radical segmentectomy for cT1N0M0/pN1-2 non-small cell lung cancer? J Thorac Cardiovasc Surg. 2012;143:820-4. 
TABLE E1. Demographic and pathologic data (segmentectomy vs lobectomy)

\begin{tabular}{|c|c|c|c|c|c|c|c|c|c|}
\hline \multirow[b]{3}{*}{ Variable } & \multirow{2}{*}{\multicolumn{3}{|c|}{ Whole patient cohort }} & \multicolumn{6}{|c|}{ Cohort for survival analysis } \\
\hline & & & & \multicolumn{3}{|c|}{ T1a } & \multicolumn{3}{|c|}{ T1b } \\
\hline & $\begin{array}{c}\text { Group L } \\
(\mathbf{n}=\mathbf{2 3 3 6})\end{array}$ & $\begin{array}{c}\text { Group } S \\
(\mathbf{n}=\mathbf{2 1 2})\end{array}$ & $P$ value & $\begin{array}{c}\text { Group } \mathbf{L} \\
(\mathbf{n}=\mathbf{2 2 2})\end{array}$ & $\begin{array}{l}\text { Group } S \\
(n=74)\end{array}$ & $P$ value & $\begin{array}{l}\text { Group L } \\
(\mathbf{n}=93)\end{array}$ & $\begin{array}{l}\text { Group S } \\
(n=31)\end{array}$ & $P$ value \\
\hline Age (y) & $67.8 \pm 10.0$ & $71.1 \pm 10.1$ & $<.01 *$ & $69.8 \pm 10.1$ & $69.8 \pm 11.9$ & .77 & $71.4 \pm 7.7$ & $71.5 \pm 8.1$ & .91 \\
\hline Gender & & & .38 & & & .95 & & & .76 \\
\hline Female & $1142(48.9)$ & $97(45.8)$ & & $112(50.5)$ & $37(50.0)$ & & $45(48.4)$ & $14(45.2)$ & \\
\hline Male & $1194(51.1)$ & $115(54.2)$ & & $110(49.5)$ & $37(50.0)$ & & $48(51.6)$ & $17(54.8)$ & \\
\hline Smoking & & & .08 & & & .79 & & & .63 \\
\hline Never & $423(18.1)$ & $26(12.3)$ & & 43 (19.4) & $16(21.6)$ & & $11(11.8)$ & $4(12.9)$ & \\
\hline Former & $1241(53.1)$ & $125(59.0)$ & & $124(55.9)$ & $38(51.4)$ & & $65(69.9)$ & $19(61.3)$ & \\
\hline Current & $672(28.8)$ & $61(28.8)$ & & $55(24.8)$ & $20(27.0)$ & & $17(18.3)$ & $8(25.8)$ & \\
\hline BMI at diagnosis $\left(\mathrm{kg} / \mathrm{m}^{2}\right)$ & $27.2 \pm 5.2$ & $26.8 \pm 6.2$ & .16 & $25.6 \pm 6.0$ & $25.4 \pm 6.2$ & .80 & $27.4 \pm 5.5$ & $28.1 \pm 6.5$ & .67 \\
\hline Cell type & & & .33 & & & .99 & & & \\
\hline Adenocarcinoma & $1362(58.3)$ & $111(52.4)$ & & $136(61.3)$ & $45(60.8)$ & & $53(57.0)$ & $18(58.1)$ & \\
\hline Squamous & $597(25.6)$ & 67 (31.6) & & $46(20.7)$ & $16(21.6)$ & & $21(22.6)$ & $5(16.1)$ & \\
\hline Small cell & $22(0.9)$ & $3(1.4)$ & & - & - & & - & - & \\
\hline Other & $355(15.2)$ & $31(14.6)$ & & $40(18.0)$ & $13(17.6)$ & & $19(20.5)$ & $8(25.8)$ & \\
\hline Grade & & & .86 & & & .56 & & & .92 \\
\hline Well & $627(26.8)$ & $56(26.4)$ & & $93(41.9)$ & $27(36.5)$ & & $33(35.5)$ & $11(35.5)$ & \\
\hline Moderate & $1086(46.5)$ & $97(45.8)$ & & $82(36.9)$ & $26(35.1)$ & & $38(40.9)$ & $11(35.5)$ & \\
\hline Poor & $421(18.0)$ & $37(17.5)$ & & $17(7.7)$ & $9(12.2)$ & & $14(15.1)$ & $6(19.4)$ & \\
\hline Nongradable & $202(8.6)$ & $22(10.4)$ & & $30(13.5)$ & $12(16.2)$ & & $8(8.5)$ & $3(9.6)$ & \\
\hline Pathologic stage & & & $<.01 *$ & & & & & & \\
\hline I & $1483(63.5)$ & $165(77.8)$ & & $222(100.0)$ & $74(100.0)$ & - & $93(100.0)$ & $31(100.0)$ & - \\
\hline II & $436(18.7)$ & $18(8.5)$ & & - & - & & - & - & \\
\hline III & $344(14.7)$ & $15(7.1)$ & & - & - & & - & - & \\
\hline IV & $51(2.2)$ & $11(5.2)$ & & - & - & & - & - & \\
\hline Limited (small cell) & $21(0.9)$ & $3(1.4)$ & & - & - & & - & - & \\
\hline Extensive (small cell) & $1(0.0)$ & $0(0.0)$ & & - & - & & - & - & \\
\hline Tumor lobe & & & $<.01 *$ & & & .12 & & & .33 \\
\hline Upper & $1348(57.7)$ & $118(55.7)$ & & $121(54.5)$ & $40(54.1)$ & & $60(64.5)$ & $19(61.3)$ & \\
\hline Middle & $175(7.5)$ & $2(0.9)$ & & $17(7.7)$ & $1(1.4)$ & & $5(5.4)$ & $0(0.0)$ & \\
\hline Lower & $813(34.8)$ & $92(43.4)$ & & $84(37.8)$ & $33(44.6)$ & & $28(30.1)$ & $12(38.7)$ & \\
\hline Tumor side & & & $.04 *$ & & & .79 & & & .17 \\
\hline Left & $965(41.3)$ & $103(48.6)$ & & $95(42.8)$ & $33(44.6)$ & & 35 (37.6) & $16(51.6)$ & \\
\hline Right & $1371(58.7)$ & $109(51.4)$ & & $127(57.2)$ & $41(55.4)$ & & $58(62.4)$ & $15(48.4)$ & \\
\hline \multicolumn{10}{|l|}{ Other comorbidity } \\
\hline COPD & $1018(43.6)$ & $129(60.8)$ & $<.01 *$ & $101(45.5)$ & $41(55.4)$ & .14 & $49(52.7)$ & $19(6.3)$ & .40 \\
\hline Cancer & $691(29.6)$ & $55(25.9)$ & .27 & $68(30.6)$ & $20(27.0)$ & .56 & $29(31.2)$ & $8(25.8)$ & .57 \\
\hline Heart disease & $498(21.3)$ & $44(20.8)$ & .85 & $62(27.9)$ & $14(18.9)$ & .12 & $20(21.5)$ & $7(22.6)$ & .9 \\
\hline Diabetes & $245(10.5)$ & $19(9.0)$ & .49 & $11(5.0)$ & $7(9.5)$ & .16 & $15(16.1)$ & $4(12.9)$ & .67 \\
\hline Kidney disease & $110(4.7)$ & $11(5.2)$ & .75 & $14(4.5)$ & $3(4.1)$ & .87 & $5(5.4)$ & $0(0.0)$ & .19 \\
\hline Liver disease & $52(2.2)$ & $4(1.9)$ & .75 & $2(0.9)$ & $2(2.7)$ & .25 & $3(3.2)$ & $0(0.0)$ & .31 \\
\hline Lung tuberculosis & $17(0.7)$ & $0(0.0)$ & .21 & $0(0.0)$ & $0(0.0)$ & - & $0(0.0)$ & $0(0.0)$ & - \\
\hline Surgical approach & & & $.03 *$ & & & .64 & & & .86 \\
\hline Muscle-sparing & $2070(88.6)$ & $177(83.5)$ & & $169(76.2)$ & $54(73.0)$ & & 85 (91.4) & $28(90.3)$ & \\
\hline VATS & $266(11.4)$ & $33(16.5)$ & & $53(23.9)$ & $20(27.0)$ & & $8(8.6)$ & $3(9.7)$ & \\
\hline Chemotherapy and/or radiotherapy $\dagger$ & & & .11 & & & .62 & & & .21 \\
\hline No & $1830(78.3)$ & $176(83.0)$ & & $213(95.9)$ & $70(94.6)$ & & $83(89.2)$ & $25(80.6)$ & \\
\hline Yes & $506(21.7)$ & $36(17.0)$ & & $9(4.1)$ & $4(5.4)$ & & $10(10.8)$ & $6(19.4)$ & \\
\hline
\end{tabular}

Data presented as mean \pm standard deviation or n (\%). L, Lobectomy; $S$, segmentectomy; BMI, body mass index; COPD, chronic obstructive pulmonary disease; VATS, video-assisted thoracic surgery. *Statistically significant. †These patients underwent radiotherapy for recurrence or progression. 
TABLE E2. Clinical features to compare postoperative complications (VATS vs thoracotomy)

\begin{tabular}{|c|c|c|c|c|c|c|c|}
\hline \multirow[b]{2}{*}{ Variable } & \multicolumn{3}{|c|}{ Total } & \multicolumn{3}{|c|}{ Matched cases by PS } & \multirow{2}{*}{$\begin{array}{c}\text { Unmatched cases } \\
\text { Thoracotomy } \\
(n=1344)\end{array}$} \\
\hline & $\begin{array}{c}\text { VATS } \\
(n=301)\end{array}$ & $\begin{array}{c}\text { Thoracotomy } \\
(n=2247)\end{array}$ & $P$ value & $\begin{array}{c}\text { VATS } \\
(\mathbf{n}=\mathbf{3 0 1})\end{array}$ & $\begin{array}{l}\text { Thoracotomy } \\
(\mathbf{n}=\mathbf{9 0 3})\end{array}$ & $P$ value & \\
\hline Age $(y)$ & $68.5 \pm 10.5$ & $68.0 \pm 10.0$ & .52 & $68.5 \pm 10.5$ & $68.5 \pm 10.4$ & .99 & $67.7 \pm 9.6$ \\
\hline Gender & & & $<.01 *$ & & & .37 & \\
\hline Female & $172(57.1)$ & $1067(47.5)$ & & $172(57.1)$ & $489(54.2)$ & & $578(43.0)$ \\
\hline Male & $129(42.9)$ & $1180(52.5)$ & & $129(42.9)$ & $414(45.8)$ & & $766(57.0)$ \\
\hline Smoking & & & .09 & & & .59 & \\
\hline Never & $64(21.3)$ & $385(17.1)$ & & $64(21.3)$ & $168(18.6)$ & & $217(16.1)$ \\
\hline Former & $163(54.2)$ & $1203(53.5)$ & & $163(54.2)$ & $510(56.5)$ & & $693(51.6)$ \\
\hline Current & $74(24.6)$ & $659(29.3)$ & & $74(24.6)$ & 225 (24.9) & & $434(32.3)$ \\
\hline Pathologic stage & & & $<.01 *$ & & & .81 & \\
\hline Early & $275(91.4)$ & $1851(82.4)$ & & $275(91.4)$ & $821(90.9)$ & & $1030(76.6)$ \\
\hline Late & $26(8.6)$ & $396(17.6)$ & & $26(8.6)$ & $82(9.1)$ & & $314(23.4)$ \\
\hline BMI at diagnosis $\left(\mathrm{kg} / \mathrm{m}^{2}\right)$ & $27.0 \pm 6.4$ & $27.2 \pm 5.3$ & .61 & $27.0 \pm 6.4$ & $26.6 \pm 5.1$ & .82 & $27.6 \pm 5.3$ \\
\hline \multicolumn{8}{|c|}{ Other diagnosis as comorbidity } \\
\hline COPD & $112(37.2)$ & $1035(46.1)$ & $<.01 *$ & $112(37.2)$ & $367(40.6)$ & .29 & 668 (49.7) \\
\hline Cancer & $62(20.6)$ & $684(30.4)$ & $<.01 *$ & $62(20.6)$ & $208(40.6)$ & .38 & $476(35.4)$ \\
\hline Heart disease & $45(15.0)$ & $497(22.1)$ & $<.01 *$ & $45(15.0)$ & $139(15.4)$ & .85 & $358(26.6)$ \\
\hline Diabetes & $19(6.3)$ & 245 (10.9) & $.01 *$ & $19(6.3)$ & $51(5.6)$ & .67 & 194 (14.4) \\
\hline Kidney disease & $17(5.6)$ & $104(4.6)$ & .43 & $17(5.6)$ & $34(3.8)$ & .16 & $70(5.2)$ \\
\hline Liver disease & $6(2.0)$ & $50(2.2)$ & .94 & $6(2.0)$ & $23(2.5)$ & .59 & $27(2.0)$ \\
\hline Lung tuberculosis & $1(0.3)$ & $16(0.7)$ & .44 & $1(0.3)$ & $10(1.1)$ & .22 & $6(0.4)$ \\
\hline
\end{tabular}

Data presented as mean \pm standard deviation or $\mathrm{n}(\%)$. Significant differences were found for gender, tumor stage, and other comorbidities (eg, COPD, cancer, heart disease, and diabetes) between the 2 groups. We matched the 2 groups with the patients undergoing the 2 approaches by the PS, incorporating the variables of age, gender, smoking status, BMI, tumor stage, and other comorbidities. After PS matching, no significant differences were found in the clinical variables between the 2 groups. VATS, Video-assisted thoracic surgery; $P S$, propensity score; $B M I$, body mass index; $C O P D$, chronic obstructive pulmonary disease. * Statistically significant.

TABLE E3. Clinical features to compare complications after thoracotomy (segmentectomy vs lobectomy)

\begin{tabular}{|c|c|c|c|c|c|c|c|}
\hline \multirow[b]{2}{*}{ Variable } & \multicolumn{3}{|c|}{ Total } & \multicolumn{3}{|c|}{ Matched cases by PS } & \multirow{2}{*}{$\begin{array}{c}\text { Unmatched cases } \\
\text { Group L } \\
(\mathbf{n}=1539)\end{array}$} \\
\hline & $\begin{array}{c}\text { Group L } \\
(\mathbf{n}=\mathbf{2 0 7 0})\end{array}$ & $\begin{array}{c}\text { Group S } \\
(\mathbf{n}=177)\end{array}$ & $P$ value & $\begin{array}{c}\text { Group L } \\
(\mathbf{n}=\mathbf{5 3 1})\end{array}$ & $\begin{array}{c}\text { Group S } \\
(\mathbf{n}=\mathbf{1 7 7})\end{array}$ & $P$ value & \\
\hline Age (y) & $67.8 \pm 10.01$ & $71.0 \pm 9.4$ & $<.01 *$ & $71.0 \pm 9.4$ & $71.0 \pm 9.4$ & .99 & $66.7 \pm 9.9$ \\
\hline Gender & & & .43 & & & .57 & \\
\hline Female & $988(47.7)$ & 79 (44.6) & & $224(42.2)$ & 79 (44.6) & & 764 (49.6) \\
\hline Male & $1082(52.3)$ & $98(55.4)$ & & $307(57.8)$ & $98(55.4)$ & & $775(50.4)$ \\
\hline Smoking & & & .13 & & & & \\
\hline Never & $363(17.5)$ & $22(12.4)$ & & $64(12.1)$ & $22(12.4)$ & .86 & $299(19.4)$ \\
\hline Former & $1097(53.0)$ & $106(59.9)$ & & $330(62.1)$ & $106(59.9)$ & & $767(49.8)$ \\
\hline Current & $610(29.5)$ & 49 (27.7) & & $137(25.8)$ & 49 (27.7) & & $473(30.7)$ \\
\hline Pathologic stage & & & .06 & & & .89 & \\
\hline Early & $1696(81.9)$ & $155(87.6)$ & & 467 (87.9) & $155(87.6)$ & & 1229 (49.6) \\
\hline Late & $374(18.1)$ & $22(12.4)$ & & $64(12.1)$ & $22(12.4)$ & & $310(20.1)$ \\
\hline BMI at diagnosis $\left(\mathrm{kg} / \mathrm{m}^{2}\right)$ & $27.2 \pm 5.2$ & $27.0 \pm 6.1$ & .39 & $27.1 \pm 4.9$ & $27.0 \pm 6.1$ & .83 & $27.2 \pm 5.3$ \\
\hline \multicolumn{8}{|c|}{ Other diagnosis as comorbidity } \\
\hline COPD & $922(44.5)$ & $113(63.8)$ & $<.01 *$ & $324(61.0)$ & $113(63.8)$ & .50 & $598(38.9)$ \\
\hline Cancer & $634(30.6)$ & $50(28.2)$ & .59 & $151(28.4)$ & $50(28.2)$ & .41 & $483(31.4)$ \\
\hline Heart disease & $456(22.0)$ & $41(23.2)$ & .64 & $151(28.4)$ & $41(23.2)$ & .17 & 305 (19.8) \\
\hline Diabetes & 229 (11.1) & $16(9.0)$ & .56 & $64(12.1)$ & $16(9.0)$ & .27 & 165 (10.7) \\
\hline Kidney disease & $96(4.6)$ & $8(4.5)$ & .99 & $16(3.0)$ & $8(4.5)$ & .34 & $80(5.2)$ \\
\hline Liver disease & $46(2.2)$ & $4(2.3)$ & .94 & $16(3.0)$ & $4(2.3)$ & .60 & $30(1.9)$ \\
\hline Lung tuberculosis & $16(0.8)$ & $0(0.0)$ & .24 & $2(0.4)$ & $0(0.0)$ & .41 & $14(0.9)$ \\
\hline
\end{tabular}

Data presented as mean \pm standard deviation or $\mathrm{n}(\%)$. Significant differences were found regarding age and other comorbidities. We matched the patients of the 2 groups by the PS and incorporating age, gender, smoking status, BMI, tumor stage, and other comorbidity (ie, COPD). After PS matching, no significant differences were found in the clinical variables between groups $\mathrm{S}$ and L. PS, Propensity score; $L$, lobectomy; $S$, segmentectomy; $B M I$, body mass index; $C O P D$, chronic obstructive pulmonary disease. *Statistically significant. 
TABLE E4. Clinical features to compare complications after VATS (segmentectomy vs lobectomy)

\begin{tabular}{|c|c|c|c|c|c|c|c|}
\hline \multirow[b]{2}{*}{ Variable } & \multicolumn{3}{|c|}{ Total } & \multicolumn{3}{|c|}{ Matched cases by PS } & \multirow{2}{*}{$\begin{array}{c}\text { Unmatched cases } \\
\text { Group L } \\
(n=161)\end{array}$} \\
\hline & $\begin{array}{c}\text { Group L } \\
(n=266)\end{array}$ & $\begin{array}{l}\text { Group S } \\
(\mathbf{n}=\mathbf{3 5})\end{array}$ & $P$ value & $\begin{array}{c}\text { Group L } \\
(\mathbf{n}=105)\end{array}$ & $\begin{array}{r}\text { Group } S \\
(\mathbf{n}=35)\end{array}$ & $P$ value & \\
\hline Age (y) & $68.1 \pm 10.1$ & $71.6 \pm 13.2$ & $.03 *$ & $71.7 \pm 10.7$ & $71.6 \pm 13.2$ & .95 & $65.7 \pm 8.9$ \\
\hline Gender & & & .47 & & & .92 & \\
\hline Female & $154(57.9)$ & $18(51.4)$ & & 51 (48.6) & 18 (51.4) & & $103(64.0)$ \\
\hline Male & $112(42.1)$ & $17(48.6)$ & & $54(51.4)$ & 17 (48.6) & & $58(9.3)$ \\
\hline Smoking & & & .20 & & & .58 & \\
\hline Never & $60(22.6)$ & $4(11.4)$ & & $18(17.1)$ & $4(11.4)$ & & $42(26.1)$ \\
\hline Former & $144(54.1)$ & $19(54.3)$ & & $59(56.2)$ & $19(54.3)$ & & $85(52.8)$ \\
\hline Current & $62(23.3)$ & $12(34.3)$ & & $28(26.7)$ & $12(34.3)$ & & $34(21.1)$ \\
\hline Pathologic stage & & & .53 & & & .36 & \\
\hline Early & 244 (91.7) & 31 (88.6) & & 98 (93.3) & 31 (88.6) & & $146(90.7)$ \\
\hline Late & $22(8.3)$ & $4(11.4)$ & & $7(6.7)$ & $4(11.4)$ & & $15(9.3)$ \\
\hline BMI at diagnosis $\left(\mathrm{kg} / \mathrm{m}^{2}\right)$ & $27.5 \pm 6.4$ & $24.6 \pm 6.6$ & .08 & $24.9 \pm 6.4$ & $24.6 \pm 6.6$ & .18 & $28.2 \pm 7.4$ \\
\hline \multicolumn{8}{|c|}{ Other diagnosis as comorbidity } \\
\hline COPD & $96(35.3)$ & $16(45.7)$ & .23 & $37(35.2)$ & $16(45.7)$ & .31 & $59(36.6)$ \\
\hline Cancer & 57 (19.2) & $5(14.3)$ & .48 & $26(24.8)$ & $5(14.3)$ & .24 & $31(19.3)$ \\
\hline Heart disease & $42(14.7)$ & $3(8.6)$ & .33 & $18(17.1)$ & $3(8.6)$ & .28 & 24 (14.9) \\
\hline Diabetes & $16(5.6)$ & $3(8.6)$ & .49 & $9(8.5)$ & $3(8.6)$ & 1.0 & $7(4.3)$ \\
\hline Kidney disease & $14(5.3)$ & $3(8.6)$ & .43 & $6(5.7)$ & $3(8.6)$ & .69 & $8(4.9)$ \\
\hline Liver disease & $6(2.3)$ & $0(0.0)$ & .37 & $4(3.8)$ & $0(0.0)$ & .57 & $2(1.2)$ \\
\hline Lung tuberculosis & $1(0.4)$ & $0(0.0)$ & .71 & $0(0.0)$ & $0(0.0)$ & - & $1(0.6)$ \\
\hline
\end{tabular}

Data presented as mean \pm standard deviation or $\mathrm{n}(\%)$. Significant differences were found regarding age. We matched the patients in the 2 groups by the PS incorporating age, gender, smoking status, BMI, and tumor stage. After PS matching, no significant difference was found in the clinical variables between groups S and L. VATS, Video-assisted thoracic surgery; $P S$, propensity score; $L$, lobectomy; $S$, segmentectomy; $B M I$, body mass index; $C O P D$, chronic obstructive pulmonary disease. *Statistically significant.

TABLE E5. Clinical features and preoperative PFT results to compare PFT changes (thoracotomy approach)

\begin{tabular}{|c|c|c|c|}
\hline Variable & $\begin{array}{c}\text { Group L } \\
(\mathbf{n}=\mathbf{5 1})\end{array}$ & $\begin{array}{l}\text { Group } S \\
(n=17)\end{array}$ & $P$ value \\
\hline Age (y) & $69.2 \pm 6.7$ & $72.2 \pm 4.8$ & .07 \\
\hline Gender & & & .78 \\
\hline Male & $29(56.9)$ & $9(52.9)$ & \\
\hline Female & $22(43.1)$ & $8(47.1)$ & \\
\hline Smoking & & & .46 \\
\hline Never & $2(3.9)$ & $2(11.8)$ & \\
\hline Former & $35(68.6)$ & $10(58.8)$ & \\
\hline Current & $14(27.5)$ & $5(29.4)$ & \\
\hline BMI at diagnosis $\left(\mathrm{kg} / \mathrm{m}^{2}\right)$ & $26.7 \pm 5.7$ & $26.7 \pm 5.2$ & .96 \\
\hline Pathologic stage & & & .11 \\
\hline Early (I-II) & $39(76.5)$ & $16(94.1)$ & \\
\hline Late (III-IV) & $12(23.5)$ & $1(5.9)$ & \\
\hline Tumor lobe & & & .33 \\
\hline Upper & $28(54.9)$ & $11(64.7)$ & \\
\hline Middle & $6(11.8)$ & $0(0.0)$ & \\
\hline Lower & $17(33.3)$ & $6(35.3)$ & \\
\hline Tumor side & & & 1.0 \\
\hline Left & $18(35.3)$ & $6(35.3)$ & \\
\hline Right & $33(64.7)$ & $11(64.7)$ & \\
\hline COPD as comorbidity & $43(86.0)$ & $14(82.4)$ & .72 \\
\hline FEV1 preoperatively & $73.5 \pm 14.3$ & $73.0 \pm 16.8$ & .87 \\
\hline FVC before operation & $81.2 \pm 16.4$ & $81.4 \pm 18.2$ & .90 \\
\hline DLCO before operation & $67.5 \pm 14.9$ & $62.6 \pm 18.9$ & .57 \\
\hline
\end{tabular}

